\title{
De la incertidumbre de emprender a la planeación estratégica: Cafetalera Alianza (From the uncertainty of entrepreneuring to strategic planning: Cafetalera Alianza)
}

\author{
Gilberto Alfredo Lu Ibarra" \\ Vinicio Horacio Santoyo-Cortés * \\ Juan José Flores-Verduzco * \\ Jesús Oaxaca Torres*
}

\begin{abstract}
More than 70\% of startups in Mexico fail during their first years of operation, mainly due to lack of strategic guidelines. Cafetalera Alianza, a micro company that sells ground coffee in Monterrey, Mexico, has three years of operations without being able to grow and consolidate in the market. To design a business plan that reduces the risk of failure, strategic tools are used such as the value net (Nalebuff et al., 1996), the ERIC matrix (Mauborgne et al., 2005) and the canvas model (Osterwalder et al., 2011). This will allow the company to know its environment and itself, and thus be able to formulate a strategy based on the theory but, mainly, on the practical.
\end{abstract}

Key words: agribusiness, business strategy, entrepreneurship, startup management

JEL: M13, M31, Q13.

\footnotetext{
- Universidad Autónoma de Chapingo, Centro de Investigaciones Económicas, Sociales y Tecnológicas de la Agroindustria y la Agricultura Mundial, Texcoco, Estado de México. Email: gilberto.lu@gmail.com

* Universidad Autónoma Chapingo, Centro de Investigaciones Económicas, Sociales y Tecnológicas de la Agroindustria y la Agricultura Mundial, Texcoco, Estado de México.

- Universidad Autónoma Chapingo, Centro de Investigaciones Económicas, Sociales y Tecnológicas de la Agroindustria y la Agricultura Mundial, Texcoco, Estado de México.

* Universidad Autónoma de Nuevo León, Facultad de Agronomía. Escobedo, Nuevo León.
} 
Resumen. Más de un $70 \%$ de las nuevas empresas en México fracasan durante sus primeros años de operaciones, principalmente por falta de directrices estratégicas. Cafetalera Alianza, una microempresa que comercializa café molido en Monterrey, México, tiene tres años de operaciones sin poder crecer y consolidarse en el mercado. Para diseñar un plan de negocios que reduzca el riesgo de fracasar, se utilizan herramientas estratégicas como la red de valor (Nalebuff et. al., 1996), la matriz ERIC (Mauborgne et. al., 2005) y el modelo de canvas (Osterwalder et. al., 2011). Esto le permitirá a la empresa conocerse y conocer su entorno y poder así, formular una estrategia con rigor metodológico, que sea factible, rentable y con un nivel de riesgo aceptable.

Palabras clave: agronegocio, dirección de microempresas, emprendedurismo, estrategia empresarial

\section{Introducción}

En México más de un $70 \%$ de las micro y pequeñas empresas que inician operaciones, fracasan durante los primeros años de sus operaciones (Lopez, 2016), por inexperiencia, por necesidad de capital, pero principalmente por la falta de directrices estratégicas que les permitan establecerse y desarrollarse adecuadamente en sus mercados durante sus primeras etapas de vida (Baker, 1993). Un ejemplo de esta situación es la que atraviesa la empresa Cafetalera Alianza, formada en Monterrey por tres estudiantes de la Facultad de Agronomía de la UANL y dedicada a la comercialización de café tostado y molido.

Desde que la empresa inició sus operaciones en 2014, Cafetalera Alianza fue aprendiendo empíricamente sobre el mercado del café en México; contactó e hizo relaciones con proveedores, desarrolló cuatro líneas de productos y comenzó su cartera de clientes (tanto distribuidores como consumidores directos).

Pero a pesar de los esfuerzos realizados, el crecimiento no fue el esperado durante los primeros meses; de sus tres socios, uno tuvo que abandonar el proyecto, y los otros dos obtuvieron empleos que les ofrecían mejores ingresos que los que la empresa les podía dar en su momento. Esto derivó en que el tiempo dedicado a las labores de la empresa fuera muy poco 0 incluso nulo.

Esto ha ocasionado que la empresa esté estancada tanto comercial como financieramente, y que se encuentre en una encrucijada por su existencia: invertir para crecer 0 aceptar su fracaso. 
Pero para invertir, más allá de establecer un plan de cómo hacer los desembolsos de capital, es necesaria la formulación de una estrategia fundamentada en los atributos y limitantes de la empresa, así como en el entorno de esta (Morales, 2009). El objetivo general de esta investigación es plantear una estrategia de fortalecimiento empresarial para la empresa Cafetalera Alianza.

A su vez, los objetivos particulares son: identificar los componentes y actores de la red de valor de la empresa Cafetalera Alianza, y analizar los distintos modelos de negocio de sus competidores con ayuda del modelo de canvas.

\section{Metodología}

El estudio fue realizado con datos históricos de la empresa Cafetalera Alianza de octubre de 2014 a octubre de 2017. También se realizó trabajo de campo con clientes de café y empresas competidoras industrializadoras de café en la ciudad de Monterrey. Así se analizó información que presentan en sus páginas de internet y referencias de sus clientes, de observación de productos en anaqueles de supermercados y de la revisión de las características de cada uno de ellos; también se recabó información mediante una encuesta de línea base de distribuidores de café y se complementó información de indicadores financieros, comerciales y operativos del modelo actual de la empresa. Además, se realizó una revisión de literatura disponible en revistas no especializadas y de los datos presentados en los informes de AMECAFÉ (2014) y de Euromonitor (2017). Para recabar datos de los proveedores, se platicó personalmente con ellos por vía telefónica, sin una encuesta predefinida.

Se utilizó la metodología propuesta por Nalebuff y Brandenburger (1996) para el análisis de la red de valor de la empresa Cafetalera Alianza; esta indica que el entorno de una empresa existen cuatro tipos de actores que interactúan con la empresa: los proveedores, los clientes, los competidores y los complementadores.

Para el análisis de los modelos de negocio de los competidores se utilizó el modelo de canvas de Osterwalder y Pigneur (2011) como base 0 guía con la cual se pudieran identificar y describir los principales aspectos de cada modelo de negocio. 
Para el diseño del nuevo modelo de negocio se elaboró un análisis FODA (Perez-Capdevila, 2011), una matriz ERIC (Mauborgne et. al., 2005) y el modelo de canvas de Osterwalder.

\section{Resultados}

\section{La red de valor de la empresa}

Cafetalera Alianza es la empresa central en la red de valor. Esta empresa realiza un proceso de semi-industrialización (en su proceso solamente muele el café tostado), empaca y comercializa.

La empresa ha desarrollado seis productos: Café Alianza Coatepec de 220 gramos y de 500 gramos, Café Alianza Soconusco de 220 gramos y de 500 gramos, Café de olla de 250 gramos y Café Los Artesanos de 340 gramos. Además de esto, cada producto se vende en presentación de kilogramo. Los proveedores de Cafetalera Alianza son dos sociedades cooperativas productoras de café, una en Unión Juárez, Chiapas y otra en Coatepec, Veracruz, quienes realizan el proceso productivo desde la cosecha hasta el tostado. Ambos cuentan con certificado con el que avalan que el café que proveen es cultivado de manera orgánica. Estas sociedades cooperativas no ofrecen ningún esquema de crédito; los pagos se realizan de contado anticipado; el envío de café se realiza por medio de empresas de diversas empresas de transportes.

Los clientes de la empresa Cafetalera Alianza no son los consumidores finales de sus productos, sino empresas que compran los productos para venderlos y obtener una ganancia con ellos, o simplemente ofrecer café como parte de sus servicios al cliente. Para conocer las diferencias que existen entre los clientes, es necesario dividirlos en dos grupos: CPK (Compradores por kilo), que pueden ser cafeterías, restaurantes, hoteles, oficinas, entre otros, y detallistas (retail), que son aquellos que cuentan con un anaquel en el que se muestran los productos al cliente o consumidor final, quien, como se comentó con anterioridad, puede adquirirlos en el establecimiento (un ejemplo de este tipo de clientes es la Tienda de productos del campo, ubicada detrás de la unidad B de la Facultad de Ciencias Biológicas de la UANL), véase Tabla 1. 
Tabla 1. Características de los grupos de clientes de Cafetalera Alianza

\begin{tabular}{|c|c|}
\hline Compradores por Kilo (CPK) & Compradores Detallistas (retailers) \\
\hline $\begin{array}{l}\text { - Lo más importante es la homogeneidad en el } \\
\text { - Un facor del café } \\
\text { - No les importa el empaque } \\
\text { - Requieren que se les entregue producto } \\
\text { cualquier día de la semana } \\
\text { - Regularmente pagan a } 30 \text { días } \\
\text { - Productos que adquieren: todos los } \\
\text { productos en kilo. }\end{array}$ & $\begin{array}{l}\text { - Regularmente tienen varias marcas de café en el } \\
\text { anaquel } \\
\text { - No les importa el precio de compra, sino el precio de } \\
\text { venta y el margen que obtienen } \\
\text { - Cobran un porcentaje por uso de su centro de } \\
\text { distribución } \\
\text { - Cobran un porcentaje por promotoría, o le piden al } \\
\text { proveedor realizar esa actividad } \\
\text { - Pagan a } 30 \text { días; algunos pagan a } 90 \text { días } \\
\text { - Productos que comercializan: Coatepec y } \\
\text { Soconusco } 220 \mathrm{~g} \text { y } 500 \mathrm{~g} \text {, olla y artesanos }\end{array}$ \\
\hline
\end{tabular}

Fuente: Elaboración propia

Los competidores de Cafetalera Alianza también tienen grandes diferencias entre sí, y para analizarlos también se distinguen entre aquellos que venden sus productos a clientes CPK o clientes de retail.

En el retail los competidores son variados, hay una diversidad extensa de empresas y marcas. Estos generalmente son empresas nacionales, presentes en la gran mayoría de los anaqueles de los principales supermercados del país. En el mercado CPK se compite con empresas regionales; estos competidores ofrecen sus productos sin diferenciación visual, con precios sumamente competitivos. Tienen relaciones estrechas con sus clientes de este mercado, por lo que es complicado quitarles participación de mercado.

Un complementador es aquél que, al incrementar las ventas de sus productos, propicia que las ventas de los productos de la empresa central se incrementen (Nalebuff et. al.,1996). Es por esto que regularmente se observa en análisis generales de la industria que el pan, la leche u otros productos alimenticios que se consumen en conjunto con el café, son complementadores.

En ocasiones se toma como complementadores a organismos gubernamentales o privados que promueven el consumo de café mexicano 0 quienes apoyan e incentivan su comercialización (dentro del país o en el extranjero); en este caso específico, la empresa no tiene nexos con alguna de estas organizaciones por lo que se considera que no tiene complementadores. 
La Figura 1 indica la red de valor de la empresa Cafetalera Alianza; de acuerdo a lo revisado anteriormente, el mercado en el que interactúa es diverso y amplio, tiene mucha facilidad para entrar en él, pero cuando se inicia, se tiene una fuerza muy pequeña en comparación a los competidores. El tipo de interacción que existe con los proveedores indica que su fuerza es superior, pues no hay lugar, por el volumen de compra, para realizar negociaciones con respecto al precio o a los plazos de crédito; los clientes también tienen una fuerza mayor, pues son ellos quienes deciden qué productos elegir ante tanta oferta. En esta situación, de acuerdo a (Porter, 1980), la empresa debería adoptar una estrategia segmentación enfocada a la diferenciación; al no tener una ventaja en costos visible en el corto plazo, se debe buscar diferenciar los productos o procesos que le generen a un segmento de mercado un valor agregado.

Figura 1. Red de valor de la empresa Cafetalera Alianza

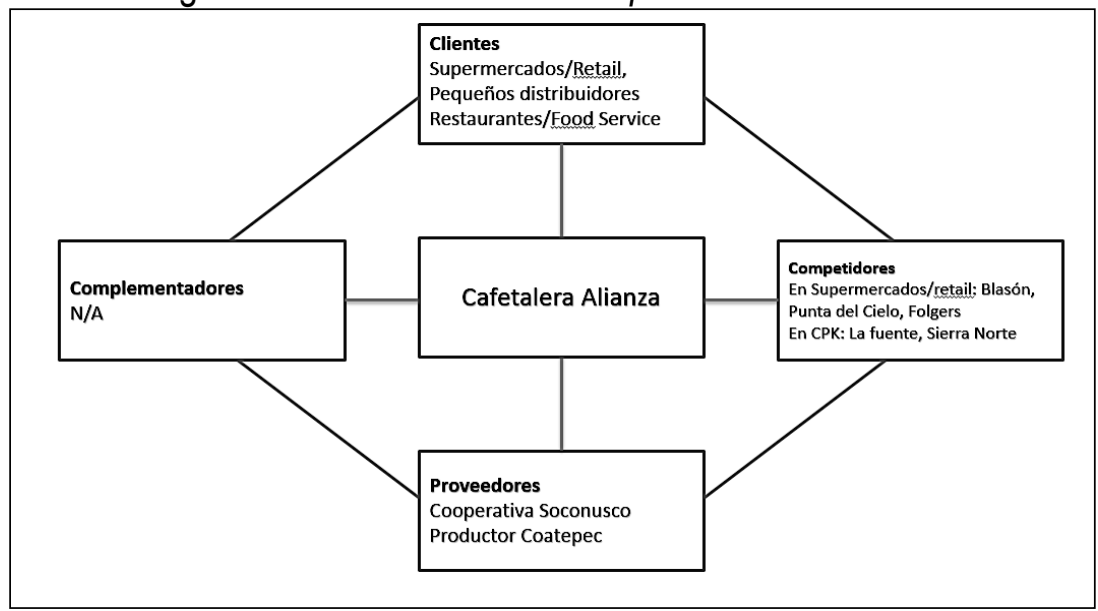

Fuente: Elaboración propia

\section{Modelos de negocio de los competidores}

Se define como modelo de negocio a la serie de procesos, procedimientos, recursos y canales de comunicación que utiliza una empresa para obtener ganancias (Osterwalder et. al., 2011). Como marco de referencia para la empresa, el análisis de lo que ya realizan los competidores en una industria (de su modelo de negocio) es importante para evaluar lo que se ha estado 
haciendo con buenos resultados y también lo que no ha funcionado, y así poder implementarlo (o no) en la organización propia (Camp, 1989).

Los competidores en el canal CPK, como se explicó en el análisis de la red, son empresas locales que ofrecen café en grandes volúmenes, de precio bajo y en empaque genérico, pero que les dan a sus clientes servicios adicionales como otorgar máquinas de café en comodato, mantenimiento de equipos o venta de productos complementarios (filtros, vasos, servilletas, azúcar o jarabes para preparar frappés, por ejemplo).

Existen dos modelos de negocio de competidores de interés para analizar por su posicionamiento en el mercado: Café La Fuente (CLF) y Café Sierra Norte (CSN). Estas dos empresas se encuentran también en Monterrey y cuentan con varias décadas de experiencia cada una. Estos dos competidores, al atender este segmento de clientes presentan similitudes en sus modelos de negocio (Figura 2) y estrategias. Si bien el mercado CPK no tiene exigencias específicas, lo más importante es que el café que compran sea económico y, por tanto, redituable. Y claro, que haya una estandarización en el sabor del café, y no haya variaciones considerables en cada lote.

Figura 2. Modelos de negocio de competidores en el mercado CPK

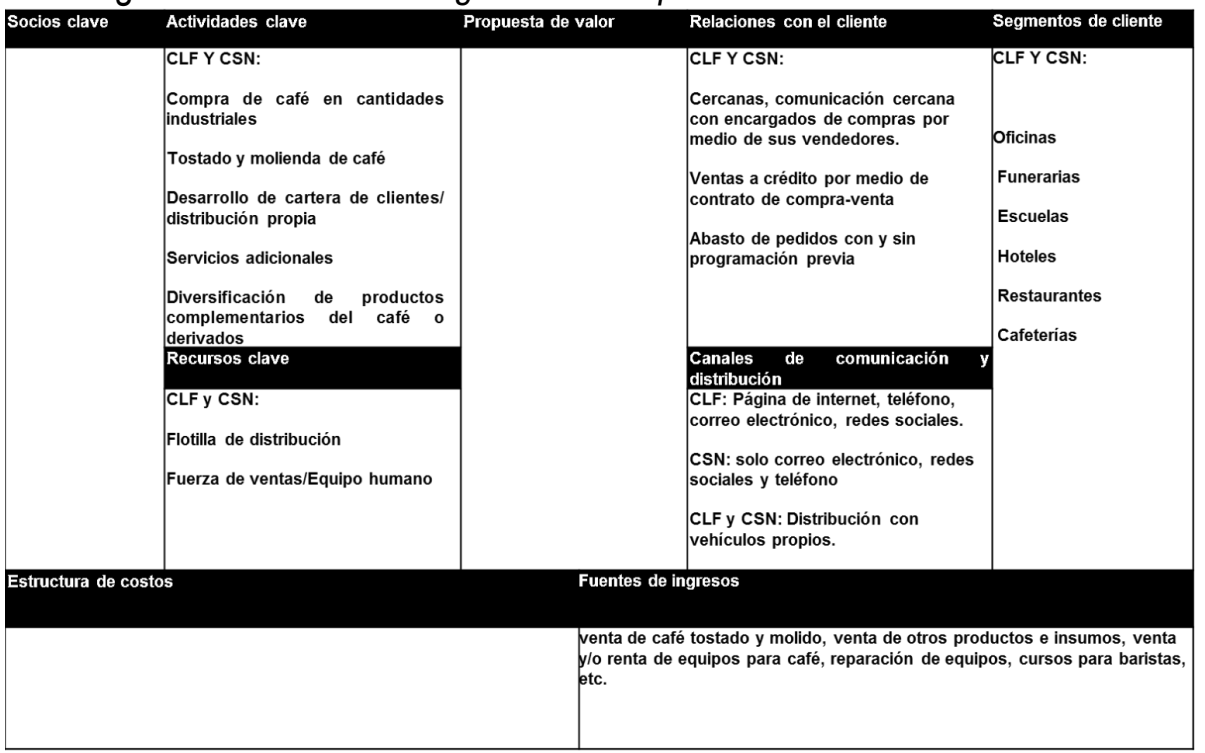

Notas: $C L F=C$ afé La Fuente $\quad C S N=$ Café Sierra Norte Fuente: Elaboración propia 
Los segmentos de clientes que atienden son mayormente del sector food service (o servicio alimentario, tales como restaurantes, cafeterías, fondas) e institucionales (oficinas, escuelas, funerarias, hoteles, hospitales, entre otros). Sus canales de comunicación son por medio de teléfono y correo electrónico, pero también el uso de redes sociales es frecuente. Incluso, en el caso de Café La Fuente, se cuenta con una página de internet donde se brinda mayor información de sus productos. Para realizar la distribución, los dos competidores cuentan con flotilla de vehículos de reparto. Los equipos de ventas que cada uno de ellos tienen hacen que las relaciones que mantienen con los clientes sean cercanas, pues el trato es directo con las personas que se encargan de las compras.

En el otro segmento de clientes, los modelos de negocio de interés son de las empresas Punta del Cielo (PDC), Blasón (BLA) y Folgers (FOL). Mientras las dos primeras son mexicanas, la tercera es una empresa estadounidense de más de un centenario de años, (véase Figura 3).

Figura 3. Modelos de negocio de competidores en el mercado retail

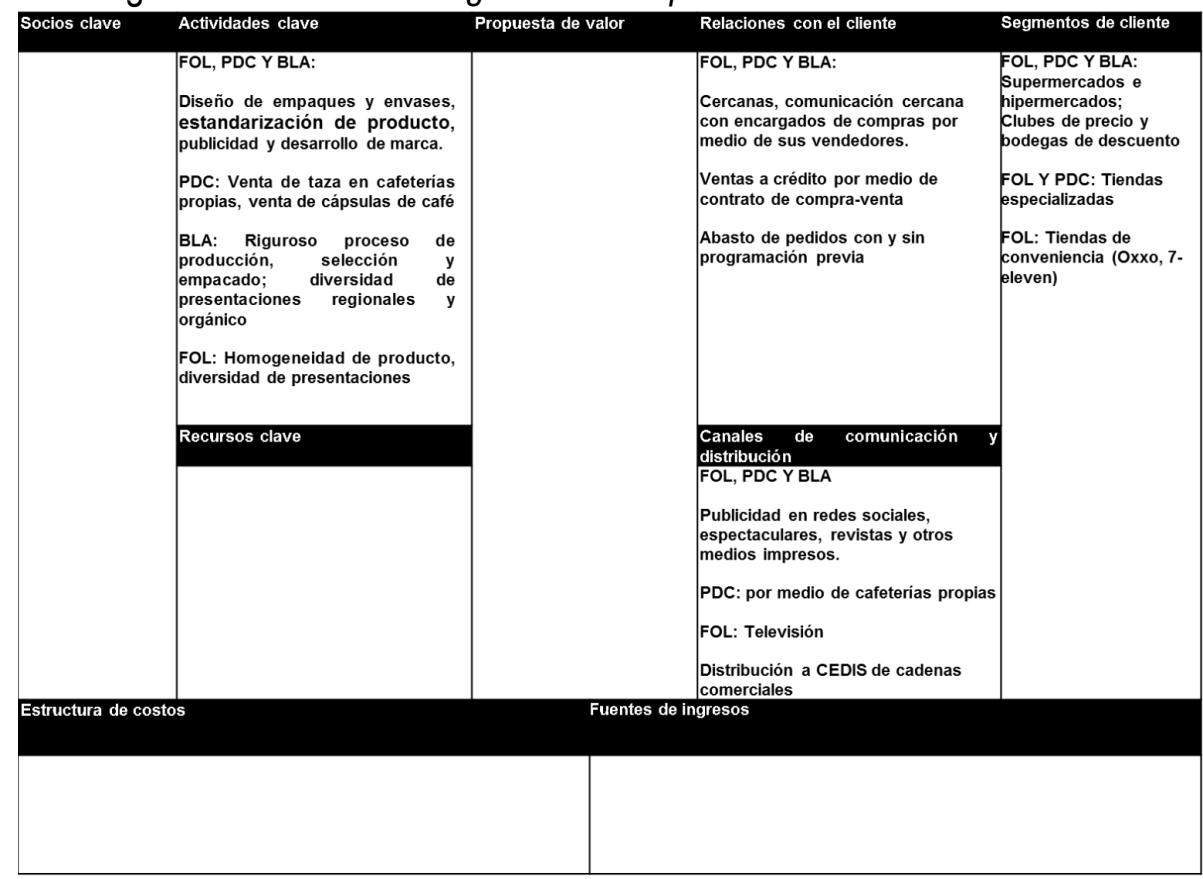

Notas: FOL=Folgers PDC=Punta del Cielo BLA:Blasón

Fuente: Elaboración propia 
Estos tres competidores están presentes en los principales tipos de establecimiento del canal retail, que son los supermercados e hipermercados y las bodegas de descuento y clubes de precios; incluso Punta del Cielo y Folgers se encuentran también presentes en tiendas especializadas (Euromonitor, 2017).

Las piezas de sus modelos de negocio de las que más se pudo obtener información por los medios al alcance, son sus segmentos de clientes, sus relaciones con el cliente, sus canales de comunicación y distribución y sus actividades clave (Figura 3).

Como se comentaba anteriormente, sus segmentos de clientes directos son supermercados e hipermercados, clubes de precio, tiendas de conveniencia y tiendas especializadas; las relaciones que estas empresas mantienen con sus clientes son cercanas, pues regularmente son entre un representante de ventas de la empresa y la persona encargada de compras del distribuidor.

Sus canales de comunicación son publicitarios, pues realizan campañas en medios masivos de comunicación, así como en redes sociales; incluso cuentan con páginas de internet donde pueden comunicarle al cliente mayor información. Su canal de distribución principal para llegar al consumidor final es el retail, al que abastecen con transportes propios 0 privados (líneas de transporte) que dan el servicio de entrega en centros de distribución.

Las actividades clave que se identifican son tres: el desarrollo del empaque (en el caso de Café Punta del Cielo es muy notoria, pues su principal innovación es la lata con sello al vacío que protege el contenido y le da mayor vida de anaquel), la publicidad y el desarrollo de sus marcas, y los procesos de estandarización de los productos que ofrecen.

Dadas las características que presenta cada uno de estos competidores, las que la empresa debería buscar incorporar a su modelo de negocio son aquellas relacionadas con la estandarización de procesos para asegurar la calidad de sus productos, la cercanía de las relaciones con los clientes por medio de un agente de ventas, y el desarrollo de canales de comunicación efectivos que permitan al consumidor final conocer a la empresa. 


\section{Análisis FODA}

El análisis FODA permite complementar el panorama que se tiene del entorno de la empresa, considerando aspectos específicos tanto internos como externos.

La empresa cuenta con algunas fortalezas: en la parte comercial, sus productos tienen un empaque diferenciado, que nadie más tiene; en la parte de capital humano, cuenta con un equipo versátil, multitareas, además de que son pocos miembros, lo cual hace que se tenga una nómina pequeña y se generen pocos gastos. Esto les permite tener una comunicación constante y mantener innovación continua de sus productos y procedimientos.

Las oportunidades que se observan son que se encuentra en un mercado en proceso de diversificación (un ejemplo de esto son las máquinas y las cápsulas de café); un mercado de productos de bajo costo al que se puede acceder con café más económico y de menos atributos de calidad; el mercado regional, el del noreste de México, es el que más gasta en café mensualmente y segundo mayor consumidor del país, lo que, sabiéndolo conjuntar en una estrategia adecuada, puede ser convertido en una fortaleza.

De acuerdo a los estudios mencionados anteriormente (Euromonitor y Amecafé), la empresa tiene oportunidad de desarrollar sus productos en los dos canales de distribución (retail y CPK), pues cada uno de ellos ha crecido en los últimos años, ganándole participación al café soluble.

Otra oportunidad es el desarrollo de mercados que valoran atributos como la calidad de taza del café, la denominación de comercio justo u orgánico, y las regiones de origen; estos nichos pagan un sobreprecio por productos que presentan estas características y la empresa puede dirigir su estrategia hacia ellos.

Las debilidades que tiene la empresa se originan por dos factores. El primero es que cuenta con capital muy limitado. A partir de esto, se tiene como consecuencia que una dificultad para acceder a mejores precios por compra de café por volumen y una dependencia de los proveedores para dar tiempos de respuesta a pedidos de manera más rápida; también por esta razón, la empresa tampoco tiene control de muchos puntos de control de estandarización y aseguramiento de la calidad del café que comercializa, lo que también es una debilidad. 
El segundo factor es que los socios fundadores no dedican suficiente tiempo al negocio, pues se dedican a sus empleos actuales. Esto ha hecho que en los años de trabajo se hayan captado pocos clientes para llegar a niveles adecuados de ingresos.

Además de las amenazas clásicas tales como una alta competitividad en el mercado y pocas barreras de entrada, existen también competidores con grandes capitales que pueden alcanzar mayores participaciones de mercado con estrategias agresivas de posicionamiento.

De acuerdo a las fortalezas, debilidades (interno), oportunidades y amenazas (externo), las acciones estratégicas que se proponen para mejorar la posición competitiva de la empresa son las que muestra la Tabla 2, entre las que destacan el desarrollo de nuevos proveedores, el aumento de capacidades comerciales, el establecimiento de parámetros y estándares de calidad, entre otros.

Tabla 2. Acciones estratégicas a partir del análisis FODA

\begin{tabular}{|c|c|c|}
\hline $\mathrm{A} / \mathrm{O}$ & Fortalezas & Debilidades \\
\hline 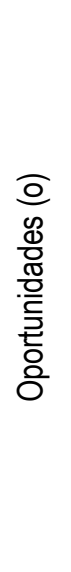 & $\begin{array}{l}\text { - Desarrollo de redes sociales y página } \\
\text { de internet como motor publicitario } \\
\text { - Desarrollar mercado CPK con alta } \\
\text { calidad en taza, orgánico y de } \\
\text { comercio justo } \\
\text { - Concentrarse en Retail de negocios } \\
\text { pequeños con producto diferenciado } \\
\text { por empaque, origen, lo artesanal y } \\
\text { cocina mexicana a precio competitivo y } \\
\text { café sin certificaciones. }\end{array}$ & $\begin{array}{l}\text { - } \text { Aumento de capacidades } \\
\text { comerciales (contratar vendedor) } \\
\text { - } \text { Cursos de barismo y caficultura a } \\
\text { empleados } \\
\text { - Adquirir tostador para aumentar } \\
\text { el control de la calidad } \\
\text { - Adquirir un local más grande } \\
\text { - Establecer parámetros de calidad } \\
\text { de recepción del café tostado } \\
\text { - Calificar calidad de café con } \\
\text { puntaje de taza } \\
\text { - Comprar café oro en lugar de } \\
\text { tostado y molido con y sin } \\
\text { certificaciones }\end{array}$ \\
\hline 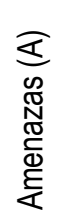 & $\begin{array}{l}\text { - Diferenciación visible de productos } \\
\text { - Diversificación de portafolio: derivados } \\
\text { como jarabes y otros, insumos para } \\
\text { cafeterías (vasos, azúcar, etc), y } \\
\text { máquinas }\end{array}$ & $\begin{array}{l}\text { - Fortalecer relaciones con } \\
\text { proveedores } \\
\text { - Desarrollar nuevos proveedores } \\
\text { - Énfasis en comercio justo y } \\
\text { cercanía con productores }\end{array}$ \\
\hline
\end{tabular}

Fuente: Elaboración propia 


\section{Matriz ERIC}

Para elaborar la matriz ERIC, se eligen los atributos que son más valorados en la industria y son evaluadas por medio de un cuadro estratégico. Para elegir las que incluyeron el cuadro estratégico de la industria del café en Monterrey (Figura 4), se utilizaron como base el café convencional y el café de especialidad.

Figura 4. Cuadro estratégico de la industria del café en Monterrey

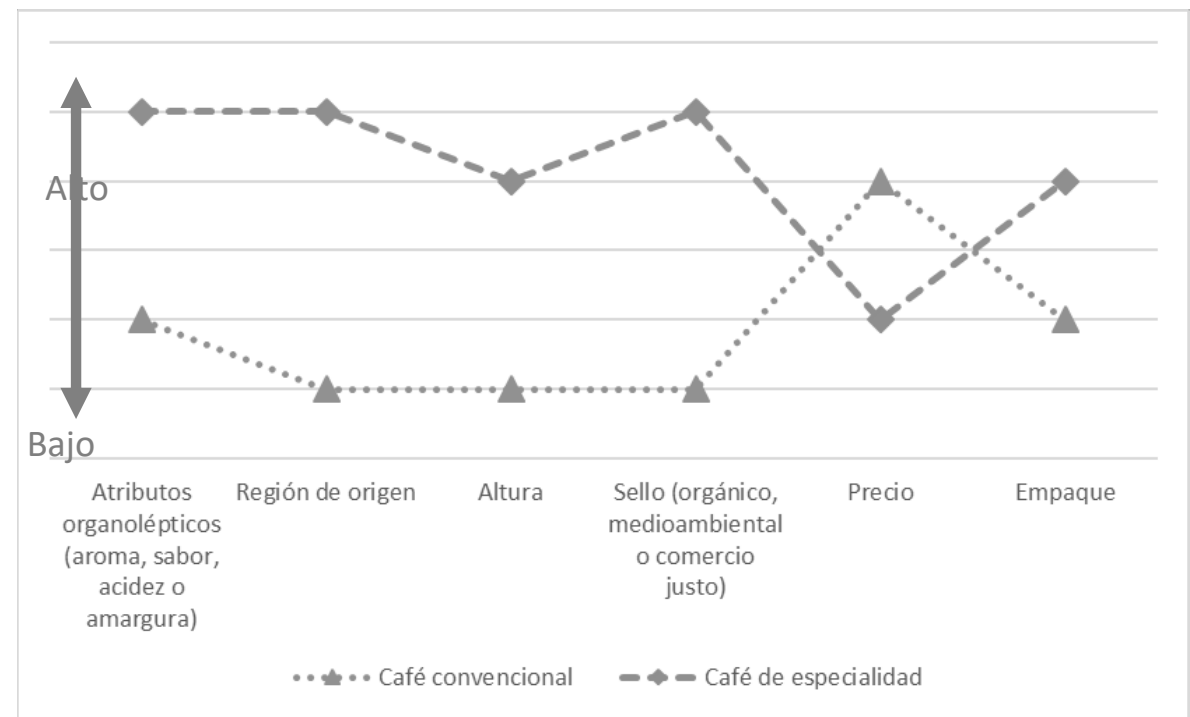

Fuente: Elaboración propia

Las atributos elegidos para realizar el comparativo son las características organolépticas (aroma, sabor, acidez o amargura), la región de origen, la altura, el sello (responsabilidad social, medioambiental, orgánico entre otros) y el precio, ya que diversos estudios como el de Sepulveda et. al. (2016) y el de Donnet et. al. (2007) concuerdan en que son las más apreciados por el consumidor.

Se identifica que, mientras en el café convencional la valoración de los atributos organolépticos, la región de origen, los datos de la altura del cultivo (metros sobre el nivel del mar) y el empaque es menor, en el café de especialidad es lo que más se valora; en el aspecto de atributos, incluso se 
otorgan puntuaciones en una escala de 100 para describir la calidad del producto. El precio es una de las características donde llegan a converger los dos tipos de café, pues es uno de los factores más importantes para la decisión de compra de café convencional, mientras en el de especialidad, es uno de los factores menos importantes para tomar esta decisión.

El cuadro estratégico de Cafetalera Alianza que semuestra en la Figura 5 agrega tres atributos que no se observan en los competidores: información sobre trazabilidad, sobre los datos sociales de las comunidades que cultivan el café que se está consumiendo, e información de cómo se acorta la cadena de valor, eliminando eslabones y dejando un mayor ingreso a los productores.

Figura 5. Cuadro estratégico de la empresa Cafetalera Alianza

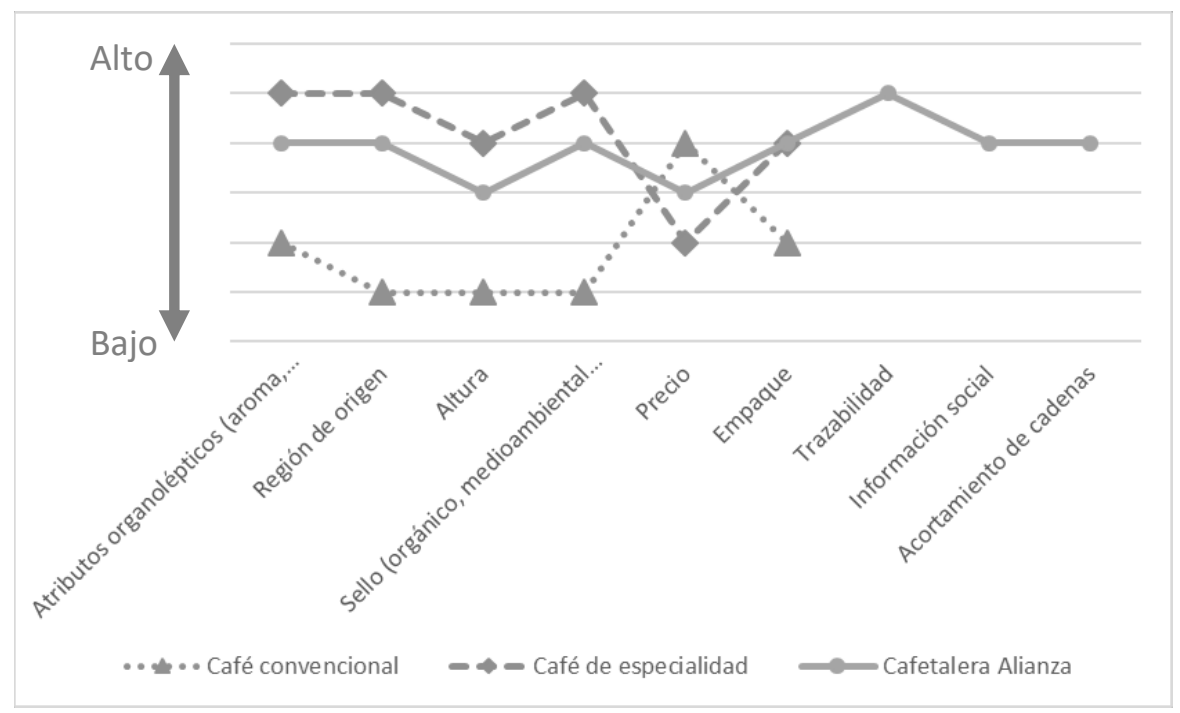

Fuente: Elaboración propia

De acuerdo a lo observado en los cuadros estratégicos y para poder lograr una diferenciación efectiva con respecto a los competidores, las acciones de la matriz ERIC de Cafetalera Alianza (Tabla 3) principalmente consisten en el enfoque a los estándares de producción para lograr una homogeneidad en los productos, en desarrollar los medios de información 
(redes sociales y página web), la creación de una fuerza de ventas y el incremento de los esfuerzos en el canal CPK.

Tabla 3. Matriz ERIC de la empresa

\begin{tabular}{ll}
\hline Acción (-) & Acción (+) \\
\hline Eliminar & Incrementar \\
Ventas sin estándares & Diferenciación de producto por certificaciones y calidad en taza \\
de calidad & Diferenciación del producto por empaque \\
Ventas a & Estandarización de producto por control de procesos \\
consignación & (almacén, molido, empaque) \\
& Esfuerzo de ventas en CPK \\
& Competitividad por precio en canal Retail \\
& Esfuerzo de ventas en canal Retail pero con pequeñas \\
& empresas. \\
& Desarrollo de medios informativos (redes, página web) \\
& Crear \\
Reducir & Ventas por calidad en taza y certificaciones (ambientales y \\
N/A & sociales) \\
& Nuevos productos: ej. Café Oro, Café Tostado en grano, \\
& según requerimientos de CPK \\
& Proceso de tostado \\
& Historia social y ambiental del origen del café \\
& Sistema de trazabilidad del café \\
& Fuerza de ventas \\
& Flotilla de reparto \\
& Espacios adecuados para procesos de producción, almacén y \\
& administrativos \\
& Alianza empresarial con Cooperativa de productores de Café \\
\hline
\end{tabular}

Fuente: Elaboración propia

\section{El nuevo modelo de negocio}

El diseño del modelo de negocio es una decisión clave para un emprendedor que crea una nueva organización porque le permite visualizar las actividades clave que debe desarrollar (Zott et. al., 2010). Con los elementos proporcionados por el análisis FODA y la matriz ERIC, se construye el nuevo modelo de negocio de la empresa Cafetalera Alianza, el cual, si bien no cambia toda la estructura del anterior modelo de negocio, si replantea 
algunos aspectos de la estrategia. Como se explicó a detalle en el análisis de la red de valor y en los modelos de negocio de los competidores, los segmentos de clientes son los que compran por kilo (CPK) y los retailers (supermercados, tiendas especializadas y otros distribuidores). A partir del análisis de estos, es posible estructurar la propuesta de valor.

De manera general, la propuesta de valor es: "Ofrecemos productos de café diferenciados por su calidad en taza, con certificaciones para proteger la salud del consumidor y la naturaleza, que reconocen socialmente a los pequeños agricultores, y que se distinguen por su presentación y garantía de trazabilidad desde su origen; a precios competitivos y con servicios adicionales".

Las redes sociales y la página de internet cumplen la función de canales de comunicación en los que se recaba y recabará gran información, opiniones directas del cliente sobre satisfacción del producto, percepción de la marca y del precio, entre otras; además se transmitirá información de la empresa, de las sociedades cooperativas proveedoras, de la trazabilidad del producto que han adquirido; por su parte, el principal canal de distribución es por medio de transporte propio, entregando ya sea en el establecimiento (en el caso de los clientes CPK y en algunos retail) o en los centros de distribución.

La relación que se lleva con el cliente es por medio de trato directo con el dueño del establecimiento, o el gerente de categoría; esto hace que se tenga una relación estrecha y no mera negociación. Se otorgará crédito de 30 días por medio de un pagaré firmado por la cantidad solicitada, y se trabajará por medio de pedido u orden de compra.

Los recursos clave para el desarrollo de la producción son el equipo de tostado y molino, la máquina selladora, la báscula; para la administración son la computadora y su respectivo sistema administrativo; para el desarrollo publicitario, la marca y los recursos electrónicos (página de internet y redes sociales), así como el recurso humano (agente de ventas) capaz de desarrollar nuevos clientes para lograr las metas de ventas

Las actividades clave que la empresa debe realizar, son las compras de materia prima por puntos en taza y certificada, establecer un control de tostado y molido y la estandarización de estos procesos, la diversificación y diferenciación de los productos por medio del diseño de empaque, manejo de redes sociales y la entrega a domicilio. Se deben establecer asociaciones 
clave con sociedades cooperativas 0 de productores que le permitan a la empresa tener mayor involucramiento y encadenamiento con este eslabón de la cadena.

Los costos del modelo de negocio actual incluirán los de producción (café, empaque y mano de obra), de ventas y administrativos (sueldos, renta, combustibles) y publicitarios (redes sociales y página de internet).

Los ingresos Cafetalera Alianza son y serán obtenidos de la venta de café molido en los distintos canales de distribución; como se ha expuesto anteriormente, cada uno de los segmentos de cliente tiene sus particularidades. Por ejemplo, el cliente de CPK compra directamente para vender el café u ofrecerlo como servicio adicional en sus instalaciones. Este tipo de cliente realiza sus pagos directamente por medio de transferencia electrónica o cheque bancario.

\section{Discusión y recomendaciones}

Con el lienzo (Figura 6) elaborado de manera gráfica, la microempresa (en este caso el emprendedor o los socios fundadores) tiene una mejor manera de evaluar cuáles son las piezas clave de su modelo de negocio.

Figura 6. Lienzo del modelo de negocio a desarrollar por Cafetalera Alianza

\begin{tabular}{|c|c|c|c|c|c|}
\hline Socios clave & Actividades clave & \multicolumn{2}{|c|}{ Propuesta de valor } & Relaciones con el cliente & Segmentos de cliente \\
\hline $\begin{array}{l}\text { Alianza } \\
\text { empresarial con } \\
\text { Cooperativa de } \\
\text { productores de } \\
\text { café }\end{array}$ & $\begin{array}{l}\text { Compras de materia prima por } \\
\text { puntos en taza y certificada, } \\
\text { Control de tostado y molido, } \\
\text { Estandarización de procesos, } \\
\text { Diversificación de productos, } \\
\text { Diferenciación de productos, } \\
\text { Entrega a domicilio }\end{array}$ & \multicolumn{2}{|c|}{$\begin{array}{l}\text { Ofrecemos productos de } \\
\text { café diferenciados por su } \\
\text { calidad en taza, con } \\
\text { certificaciones para } \\
\text { proteger la salud del } \\
\text { consumidor y la naturaleza, } \\
\text { que reconocen socialmente } \\
\text { a los pequeños } \\
\text { agricultores, y que se } \\
\text { distinguen por su } \\
\text { presentación y garantia de } \\
\text { trazabilidad desde su } \\
\text { origen; a precios } \\
\text { competitivos y con } \\
\text { servicios adicionales }\end{array}$} & $\begin{array}{l}\text { Comunicación cercana y trato } \\
\text { directo, Orden de compra y } \\
\text { programación de abasto, Crédito }\end{array}$ & $\begin{array}{c}\text { CPK: Restaurantes, } \\
\text { hoteles, funerarias, } \\
\text { hospitales, comedores } \\
\text { industriales, escuelas, } \\
\text { oficinas. } \\
\text { Retail: tiendas } \\
\text { especializadas, } \\
\text { supermercados } \\
\text { locales y regionales. }\end{array}$ \\
\hline \multicolumn{6}{|c|}{ Estructura de costos } \\
\hline \multicolumn{3}{|c|}{$\begin{array}{c}\text { Café pergamino }+ \text { costos de proceso (servicios }+ \text { empaque }+ \text { mano de } \\
\text { obra }+ \text { depreciación de maquinaria }+ \text { mantenimiento) }+ \text { gastos } \\
\text { administrativos y de venta }+ \text { gastos logisticos }+ \text { gastos publicitarios y } \\
\text { promocionales }\end{array}$} & \multicolumn{3}{|c|}{$\begin{array}{l}\text { Venta de café tostado y molido en distintas presentaciones y gramajes } \\
\text { Retail } 24 \% \text { de margen bruto en promedio } \\
\text { CPK, } 60 \% \text { de margen bruto en promedio }\end{array}$} \\
\hline
\end{tabular}

Fuente: Elaboración propia 
Se observa entonces que, para realizar un análisis de mayor precisión de la empresa, es de gran ayuda utilizar las herramientas antes expuestas. La red de valor (el conocimiento de los actores principales y de sus fuerzas dentro de ella) y la matriz ERIC (con todo el proceso de construcción previo) para conocer el entorno de la empresa. El análisis FODA y el modelo de canvas, para realizar un ejercicio de introspección y detectar de manera efectiva cómo la empresa interactúa con su entorno.

De esta forma, los objetivos de la investigación se cumplieron: se logró identificar a los actores clave de la red de valor en la que participa la empresa y se analizaron los elementos más importantes de los modelos de negocio de competidores más cercanos por medio del modelo de canvas (objetivos particulares), para posteriormente plantear una estrategia empresarial para Cafetalera Alianza (objetivo general).

Surgen dos recomendaciones para las PYMES que están iniciando operaciones y que en su momento usarán las herramientas en este artículo descritas. La primera recomendación es que al formular un proyecto financiero, ya sea para invertir en la empresa (si se cuenta con los recursos) o para atraer la atención de inversionistas, se utilicen directrices estratégicas fundamentadas en bases teóricas y en datos reales; esto le da a cualquier propuesta mayor credibilidad e incluso, posibilidades de éxito al emprenderla.

La segunda recomendación es que es importante considerar que toda estrategia tiene una vigencia mayor o menor, dependiendo de la intensidad competitiva y de las acciones de la industria; es necesario mantener siempre una mentalidad estratégica que le permita a la empresa mantener su competitividad y estar alerta para cualquier cambio que se presente en la industria en la que se encuentra.

\section{Referencias}

AMECAFE. (2014). Segmentación de consumidores de café. Ciudad de México: Asociación Mexicana de la Cedena Productiva del Café.

Baker, W. H. (1993). Business planning small firms in successful, Long Range Planning, 26(6), 82-88.

Camp, R. C. (1989). Benchmarking: The search for industry best practices that lead to superior performance. Milwaukee, WIS : ASQC Qual Press. 
Donnet, M. L., Weatherspoon, D. D. \& Hoehn, J. P. (2007). What adds value in specialty coffee? managerial implications form hedonic price analysis of Central and South American E-Auctions. International Food and Agribusiness Management Review, 10(3), 1-18.

Euromonitor \& Amecafe. (2017). Análisis del mercado de consumo de café en México 2016. Londres: Eurimonitor Consulting.

Lopez, J. (2016). Fracasan en México 75\% de emprendimientos. El Financiero, Empresas, Recuperado de: http://www.elfinanciero.com.mx/empresas/fracasan-en-mexico-75de-emprendimientos.html

Mauborgne, R. \& Kim, W. C. (2005). Blue ocean strategy: How to create uncontested market space and make the competition irrelevant (1st ed.). Boston, Mass: Harvard Business School Publishing Corporation.

Morales, A. \& Morales, J. A. (2009). Proyectos de inversión. Evaluación y formulación (1st ed.). Cd. de México: McGraw-Hill.

Nalebuff, B. J. \& Brandenburger, A. M. (1996). Coo-petencia (1ra ed.). Nueva York: Currency Books.

Osterwalder, A. \& Pigneur, Y. (2011). Generación de modelos de negocio: Un manual para visionarios, revolucionarios y retadores. Barcelona: Deusto.

Osterwalder, A., Pigneur, Y., Bernarda, G. \& Smith, A. (2014). Value proposition design. Strategyzer series, Journal of Business Models, 3(1), 81-92.

Perez-Capdevila, J. (2011). Óbito y resurrección del análisis DAFO. Revista Avanzada Científica, 14(2), 1-11.

Porter, M. E. (1980). Estrategia competitiva: técnicas para el análisis de los sectores industriales y de la competencia. Cd. de México: CECSA. Título original: Competitive Strategy: techniques for analyzing industries and competitors. New York: The Free Press.

Sepulveda, W. S., Chekmam, L., Maza, M. T. \& Mancilla, N. O. (2016). Consumers' preference for the origin and quality attributes associated with production of specialty coffees: Results from a cross-cultural study, Food Research International, 89(2), 997-1003.

Zott, C., \& Amit, R. (2010). Business model design: An activity system perspective, Long Range Planning, 43(2-3), 216-226. 